\title{
Prevalence and Antimicrobial Resistance of Salmonella enterica Isolated from Chicken and Guinea Fowl in Burkina Faso
}

\author{
Soutongnooma Caroline Bouda ${ }^{1,3}$, Assèta Kagambèga ${ }^{1,2}$, Laetitia Bonifait ${ }^{3}$, Françoise Le Gall ${ }^{3}$, \\ Hadiza Bawa Ibrahim ${ }^{1}$, Evariste Bako', Toudwensida Serge Bagre ${ }^{1}$, Cheickna Zongo ${ }^{1}$, \\ Aïssata Wereme N'diaye ${ }^{4}$, Sababenejo Alfred Traore ${ }^{1}$, Marianne Chemaly ${ }^{3}$, Gilles Salvat ${ }^{3}$, \\ Nicolas Barro ${ }^{1}$
}

${ }^{1}$ Department of Biochemistry and Microbiology, University of Ouaga I, Ouagadougou, Burkina Faso

${ }^{2}$ Departement of Biology, Institute of Sciences (IDS), Ouagadougou, Burkina Faso

${ }^{3}$ National Agency for Food, Environment and Work Security (ANSES), Ploufragan-Plouzané, France

${ }^{4}$ National Institute for Environment and Agricultural Research CNRST / INERA / CREAF, Ouagadougou, Burkina Faso

\section{Email address:}

kagambega.asseta@gmail.com (A. Kagambèga)

To cite this article:

Soutongnooma Caroline Bouda, Assèta Kagambèga, Laetitia Bonifait, Françoise Le Gall, Hadiza Bawa Ibrahim, Evariste Bako, Toudwensida Serge Bagre, Cheickna Zongo, Aïssata Wereme N'diaye, Sababenejo Alfred Traore, Marianne Chemaly, Gilles Salvat, Nicolas Barro. Prevalence and Antimicrobial Resistance of Salmonella enterica Isolated from Chicken and Guinea Fowl in Burkina Faso. International Journal of Microbiology and Biotechnology. Vol. 4, No. 3, 2019, pp. 64-71. doi: 10.11648/j.ijmb.20190403.12

Received: June 8, 2019; Accepted: July 16, 2019; Published: July 31, 2019

\begin{abstract}
Consumption of contaminated poultry and poultry products by Salmonella is a public health problem worldwide. The aim of this study was to determine the prevalence, serotypes and antibiotic susceptibility of Salmonella isolated from slaughtered poultry. A total of 563 intestine samples from slaughtered chickens $(n=283)$ and guinea fowl ( $\mathrm{n}=280)$ were collected from 7 open markets in 2 urban and 2 rural areas of Burkina Faso. The samples were processed for the isolation and identification of associated Salmonella using microbiological standard methods. The suspected colonies were subjected to biochemical tests and serotyped by slide agglutination test according to Kauffman-White scheme. Antibiotic sensitivity patterns of Salmonella were also investigated using commonly used antibiotics. Of the 563 intestines samples, 139 (24.69\%) isolates were recovered, with 59/283 (20.84\%) isolates from chicken and 80/280 (28.57\%) isolates from guinea fowl. The successful serotyping of 109/139 isolates revealed 9 serotypes namely Typhimurium, Kentucky, Ouakam, Brancaster, Hato, Kaapstad, Essen, Chester, and Derby. Five strains were untypable and 15 belong to different serogroups such as B, M, E, D, F, and O. The serotypes Brancaster, Chester, Derby, Hato, and Typhimurium were found in chicken and guinea fowl. $S$. Kaapstad was detected only on guinea fowl and $S$. Essen, Kentucky and Ouakam on chicken. Serotype Derby (38.84\%), Chester (11.51\%) and Hato (10.07\%), Typhimurium (8.63\%) were the most prevalent. Out of the 139 isolates, $100 \%$ show resistance to at least one antibiotic (Erythromycin), while, 50 (35.97\%) were multi-resistant. High sensitivity of isolates was recorded for Chloramphenicol, Ciprofloxacin, Nalidixic acid, Cephalexin, Sulfamethoxazole-trimethoprim and Colistin Sulfate. The data confirm that poultry is a potential reservoir of Salmonella. This recommends good hygienic practices when producing poultry carcasses.
\end{abstract}

Keywords: Salmonella Serotypes, Antimicrobial Resistance, Chicken, Guinea Fowl, Burkina Faso

\section{Introduction}

Non-typhoidal Salmonella (NTS) is considered one of the most common causes of foodborne human infections worldwide [1]. More than 2610 Salmonella enterica serovars have been recognized worldwide, most of them being major causative agents of diseases in humans and animals, producing gastroenteritis and other acute infections [2]. 
Nontyphoidal Salmonella spp. is the primary bacterial pathogen causing foodborne illness and the leading cause of hospitalization among the top five foodborne pathogens in the United States [3]. According to food poisoning statistics from the Infectious Disease Surveillance Center in Japan, there were 93,444 bacterial foodborne illnesses between 1999 and 2002, and $32 \%$ of these cases were salmonellosis [4]. Unfortunately, in Sub-Saharan Africa, the foodborne diseases are more frequent with high morbidity and mortality but still underestimated because of the lack of foodborne pathogens surveillance system. However, the World Health Organisation estimated that the African region has the highest burden of foodborne diseases with more than 91 million cases and 137,000 deaths each year [5]. Salmonella has been reported to be the second most pathogen affecting foodborne illnesses in Burkina Faso [6, 7]. Poultry is an important reservoir of many zoonotically pathogens, mainly Salmonella and Campylobacter [8, 9]. Poultry meat can acquire Salmonella from intestinal contents, faecal material or from cross-contamination during slaughtering processes [10]. In Sub-Saharan African countries and particularly in Burkina Faso, there is an emergence of poultry farming and it's encouraged by the government for agricultural development, but this activity is dominated by artisanal technologies that lead to human and animal illnesses. In Burkina Faso it's characterized by a system of family farms dispersed in small production units. Traditional livestock farming is characterized by the natural breeding of poultry, rudimentary animal husbandry techniques and equipment, food and water supply, and veterinary health monitoring is virtually absent. Traditional poultry plays a major role in the quest for self-sufficiency and sustainability of food security and contributes to the religious, social and cultural livelihoods of the rural population [11]. In addition, traditional poultry is a source of income for poor farmers in rural areas, especially women, [11].

In recent years, there has been growing public health concern over the worldwide emergence of antibiotic-resistant strains of a number of pathogenic bacteria, including Salmonella. Although most cases of human salmonellosis are self-limiting and typically resolved in five to seven days without antimicrobial treatment, antibiotic therapy may be necessary for severe cases, extra-intestinal disease or immunecompromised patients [12]. In this case, resistant Salmonella strains are especially threatening because they may compromise the effective treatment of human salmonellosis.

In developing countries, the main factor which contributes to increase the development of antibiotic-resistant bacteria is the use of the same type of antibiotics in veterinary medicine for infection treatment as well as growth promoters and in human medicine for diseases treatment. For all the above, there is an urgent need to prevent human salmonellosis particularly in developing countries and that requires prior monitoring of Salmonella from animal origin. The aims of this study were to isolate, identify, serotyped and to determine the antimicrobial susceptibility of Salmonella enterica strains isolated from faecal samples of chicken and guinea fowl to obtain data to contribute to the control and to determine the dissemination of Salmonella serovars.

\section{Material and Methods}

\subsection{Period and Samples Collection}

From February to September 2016, 563 intestine samples from slaughtered chicken $(n=283)$ and guinea fowl $(n=280)$ were collected in seven markets in two cities and two villages. Samples were conditioned into sterile bags and placed at $4^{\circ} \mathrm{C}$ to the laboratory for microbiological analysis within six hours.

\subsection{Samples Processing for Isolation of Salmonella}

Samples were processed for Salmonella isolation and identification according to the International Organization for Standardization norm 6579-2017 [13]. For pre-enrichment and enrichment step, $10 \mathrm{~g}$ of cecal contents were homogenized in $90 \mathrm{~mL}$ of sterile buffered peptone water (Liofilchem, France) incubated at $37^{\circ} \mathrm{C}$ for $24 \mathrm{~h}$ and $1 \mathrm{~mL}$ was transferred into $10 \mathrm{~mL}$ of Muller-Kauffmann broth novobiocin tetrathionate (MKTTn) (OXOID, England) and $0.1 \mathrm{~mL}$ on MSRV agar (modified semi-solid agar medium of Rappaport- Vassiliadis) (OXOID, England), then, plates were incubated at $41^{\circ} \mathrm{C}$ for $24 \mathrm{~h}$.

A loop full of culture from MKTTn enriched broth was also subcultured onto Xylose Lysine tergitol 4 (XLT4) and Xylose Lysine desoxycholate (XLD) agar plates respectively and incubated aerobically at $37^{\circ} \mathrm{C}$ for $24 \mathrm{~h}$. The suspected Salmonella were transferred onto nutrient agar plates and subsequently subjected to pre-identification tests: catalase and peroxidase production, the oxidation/fermentation test, production of indol and $\mathrm{H}_{2} \mathrm{~S}$, and fermentation of glucose, lactose and urea [14].

Salmonella strains were confirmed with the API20E Kit (Biomerieux, Marcy l'Etoile, France). The strains were stored in Broth brain heart supplemented with 30\% of glycerol at $-20^{\circ} \mathrm{C}$ for further characterization.

\subsection{Serotyping and Antimicrobial Susceptibility Testing of Salmonella Isolates}

The confirmed strains were serotyped by slide agglutination test according to Kauffman-White scheme [15] in the laboratory (Anses, Hygiene and Quality of Poultry and Pig Products Unit, France).

The antimicrobial susceptibility tests were performed on Mueller Hinton agar using the disk diffusion method [16]. Interpretation of MICs and zone diameters was done according to the European Committee on Antimicrobial Susceptibility Testing [17] and the strains with intermediate resistance to any antibiotic did not count as resistant. The antimicrobials tested were gentamicin (GEN; $10 \mu \mathrm{g}$ ), Streptomycin (STR; $10 \mu \mathrm{g}$ ), Aztreonam (AZT; $30 \mu \mathrm{g}$ ), Ticarcillin (TC; $75 \mu \mathrm{g}$ ), Imipenem (IPM; $10 \mu \mathrm{g}$ ), Amoxicillin-clavulanic-acid (AMC; $30 \mu \mathrm{g}$ ), Cephalexin (CL; $30 \mu \mathrm{g}$ ), Sulfamethoxazole-trimethoprim (SXT; $25 \mu \mathrm{g}$ ), 
Erythromycin (E; $15 \mu \mathrm{g})$, Colistin Sulfate $(10 \mu \mathrm{g})$, Chloramphenicol (C; $30 \mu \mathrm{g})$, Cefotaxime (CTX; $5 \mu \mathrm{g}$ ), Ceftriaxone (CTR; $30 \mu \mathrm{g}$ ), Ciprofloxacin (CIP; $5 \mu \mathrm{g}$ ), Nalidixic acid (NA; $30 \mu \mathrm{g}$ ), Tetracycline (TE; $30 \mu \mathrm{g}$ ) (Liofilchem, France).

\section{Results}

\subsection{Prevalence and Serotypes Distribution}

Salmonella was detected from 139/563 (24.69\%), with $59 / 283$ (20.84\%) from chicken and 80/280 (28.57\%) from guinea fowl (Table 1).

Table 1. Prevalence of Salmonella in local chicken and Guinea fowl from differents localisations.

\begin{tabular}{|c|c|c|c|}
\hline \multicolumn{2}{|c|}{ localities } & Local chicken & Guinea fowl \\
\hline \multirow{2}{*}{ Urban } & Ouagadougou & $31 / 128(23.44 \%)$ & $27 / 126(21.43 \%)$ \\
\hline & Bobo Dioulasso & $18 / 130(13.08 \%)$ & $28 / 127(22.05 \%)$ \\
\hline \multirow{2}{*}{ Rural } & Poa & $4 / 13(30.77 \%)$ & $4 / 12(33.33 \%)$ \\
\hline & Djibasso & $6 / 13(46.15 \%)$ & $8 / 14(57.14 \%)$ \\
\hline \multicolumn{2}{|c|}{ Total per species } & $59 / 284(20.07 \%)$ & $80 / 279(24.01 \%)$ \\
\hline \multicolumn{2}{|c|}{ Total } & $124 / 563(57.11 \%)$ & \\
\hline
\end{tabular}

Among the 139 strains isolated, 109 of them could be serotyped and they were found to belong to 9 serotypes namely Typhimurium, Kentucky, Ouakam, Brancaster, Hato, Kaapstad, Essen, Chester, and Derby. Five strains were untypable and 15 belong to different serogroups such as B, M, E, D, F, and O. Serotypes Brancaster, Chester, Derby, Hato, and Typhimurium were present in chicken and guinea fowl. S. Kaapstad was only found on guinea fowl whereas S. Essen, Kentucky and Ouakam were detected on chicken Serotype Derby, Chester, Hato and Typhimurium were the most prevalent.

\subsection{Antimicrobial Susceptibility Test}

Antimicrobial susceptibility testing of the isolates (chicken and guinea fowl) revealed absolute resistance to Erythromycin $\quad(100 \%)$, while $50 \quad(35.97 \%)$ were multiresistant; More than half of the isolates showed resistance to Amoxicillin-clavulanic acid (63.33\% of chicken isolates and $60.97 \%$ of guinea fowl isolates) followed by Ticarcillin $(60 \%$ of chicken isolates and $51.21 \%$ of guinea fowl isolates). The high sensitivity of isolates was recorded for Chloramphenicol, Ciprofloxacin, Nalidixic acid, Cephalexin, Sulfamethoxazole-trimethoprim and Colistin sulfate (Tables 2 and 3).

Table 2. Details of different serotypes of Salmonella enterica obtained from different species of poultry.

\begin{tabular}{llll}
\hline \multirow{2}{*}{$\begin{array}{l}\text { Salmonella } \\
\text { serovars }\end{array}$} & Origin & \multirow{2}{*}{ Total } \\
\cline { 2 - 3 } guinea fowl & chicken & \\
\hline S. Brancaster & $5(6.25)$ & $1(1.70)$ & $6(4.31)$ \\
S. Chester & $6(7.5)$ & $10(16.95)$ & $16(11.51)$ \\
S. Kaapstad & $4(5.00)$ & - & $4(2.87)$ \\
S. Derby & $36(45.00)$ & $18(30.50)$ & $54(38.84)$ \\
S. Essen & - & $1(1.70)$ & $1(0.72)$ \\
S. Hato & $6(7.50)$ & $8(13.55)$ & $14(10.07)$ \\
S. Kentucky & - & $1(1.70)$ & $1(0.72)$ \\
S. Ouakam & - & $1(1.70)$ & $1(0.72)$ \\
\hline
\end{tabular}

\begin{tabular}{llll}
\hline $\begin{array}{l}\text { Salmonella } \\
\text { serovars }\end{array}$ & Origin & \multicolumn{2}{c}{ Total } \\
\cline { 2 - 4 } & guinea fowl & chicken & \\
\hline S. Typhimurium & $11(13.75)$ & $1(1.70)$ & $12(8.63)$ \\
S. Group B & $2(2.50)$ & $1(1.70)$ & $3(2.15)$ \\
S. Group O & - & $1(1.70)$ & $1(0.72)$ \\
S. Group E & $2(2.50)$ & $2(3.38)$ & $4(2.87)$ \\
S. Group F & $1(1.25)$ & $3(5.08)$ & $4(2.87)$ \\
S. Group M & - & $1(1.70)$ & $1(0.72)$ \\
S. Group D & $2(2.50)$ & $1(1.70)$ & $3(2.15)$ \\
Untypable & $5(6.25)$ & $9(15.25)$ & $14(10.07)$ \\
Total & $80(28.57 \%)$ & $59(20.84 \%)$ & $139(24.69 \%)$ \\
\hline
\end{tabular}

Table 3. Antibiogram results of Salmonella isolates from chicken $(n=59)$.

\begin{tabular}{llll}
\hline Antibiotics & Resistant (n(\%)) & \%intermediate & \% sensible \\
\hline AZT $(30 \mu \mathrm{g})$ & $8(13.33 \%)$ & $29(48.33 \%)$ & $23(38.33 \%)$ \\
AMC $(30 \mu \mathrm{g})$ & $38(63.33 \%)$ & 0 & $22(36.66 \%)$ \\
TC $(75 \mu \mathrm{g})$ & $36(60 \%)$ & 0 & $24(40 \%)$ \\
IPM $(10 \mu \mathrm{g})$ & 0 & $16(26.66 \%)$ & $44(73.33 \%)$ \\
CL $(30 \mu \mathrm{g})$ & $2(3.33 \%)$ & 0 & $58(96.66 \%)$ \\
CTR $(30 \mu \mathrm{g})$ & $3(5 \%)$ & $14(23.33 \%)$ & $43(71.66 \%)$ \\
CTX $(5 \mu \mathrm{g})$ & $5(8.33 \%)$ & $12(20 \%)$ & $43(71.66 \%)$ \\
S $(10 \mu \mathrm{g})$ & $6(10 \%)$ & $31(51.66)$ & $23(38.33 \%)$ \\
GEN $(10 \mu \mathrm{g})$ & $7(11.66 \%)$ & $14(23.33 \%)$ & $39(65 \%)$ \\
C $(30 \mu \mathrm{g})$ & $1(1.66 \%)$ & 0 & $59(98.33 \%)$ \\
TE $(30 \mu \mathrm{g})$ & $19(31.66)$ & $12(20 \%)$ & $29(43.33 \%)$ \\
Na $(30 \mu \mathrm{g})$ & 0 & $1(1.66)$ & $59(98.33 \%)$ \\
CIP $(5 \mu \mathrm{g})$ & $2(3.33 \%)$ & $21(35 \%)$ & $37(61.66 \%)$ \\
SXT $(25 \mu \mathrm{g})$ & $5(8.33 \%)$ & 0 & $55(91.66 \%)$ \\
CS $(10 \mu \mathrm{g})$ & $14(23.33 \%)$ & 0 & $46(76.66 \%)$ \\
\hline
\end{tabular}

Gentamicin: GEN, Streptomycin: STR, Aztreonam: AZT, Ticarcillin: TC, Imipenem: IPM, Amoxicillin-clavulanic-acid: AMC, Cephalexin: CL, Sulfamethoxazole-trimethoprim: SXT, Colistin Sulfat: Cs, Chloramphenicol: C, Cefotaxim: CTX, Ceftriaxon: CTR, Ciprofloxacin: CIP, Nalidixic acid: NA, Tetracycline: TE

Susceptibility to other antimicrobials was variable 22 strains show resistance to 3 or 4 antibiotics and 17 show resistances to 5 or more antibiotics (Tables 4 and 5).

Table 4. Antibiograms results of Salmonella isolates from guinea fowl $(n=$ 80).

\begin{tabular}{llll}
\hline Antibiotics & Resistant & Intermediate & Sensitive \\
\hline AZT $(30 \mu \mathrm{g})$ & $15(18.29)$ & $32(32.02)$ & $33(41.25 \%)$ \\
AMC $(30 \mu \mathrm{g})$ & $50(60.97)$ & 0 & $30(37.5 \%)$ \\
TC $(75 \mu \mathrm{g})$ & $42(51.21 \%)$ & 0 & $38(47.5 \%)$ \\
IPM $(10 \mu \mathrm{g})$ & $1(1.21 \%)$ & $19(23.17 \%)$ & $60(75 \%)$ \\
CL $(30 \mu \mathrm{g})$ & $5(6.09 \%)$ & 0 & $75(93.75 \%)$ \\
CTR $(30 \mu \mathrm{g})$ & $3(3.65 \%)$ & $30(36.58 \%)$ & $47(58.75 \%)$ \\
CTX $(5 \mu \mathrm{g})$ & $27(32.92 \%)$ & $18(21.95 \%)$ & $45(56.25 \%)$ \\
S $(10 \mu \mathrm{g})$ & $10(12.19 \%)$ & $35(42.68 \%)$ & $35(43.75 \%)$ \\
GEN $(10 \mu \mathrm{g})$ & $6(7.31 \%)$ & $12(14.63 \%)$ & $62(77.5 \%)$ \\
C $(30 \mu \mathrm{g})$ & $2(2.43 \%)$ & 0 & $78(97.5 \%)$ \\
TE $(30 \mu \mathrm{g})$ & $29(35.36 \%)$ & $15(18.29 \%)$ & $36(45 \%)$ \\
Na $(30 \mu \mathrm{g})$ & $1(1.21 \%)$ & $5(6.09 \%)$ & $74(92.5 \%)$ \\
CIP $(5 \mu \mathrm{g})$ & $8(9.75 \%)$ & $12(14.63 \%)$ & $60(75 \%)$ \\
SXT $(25 \mu \mathrm{g})$ & $1(1.2 \%)$ & 0 & $79(98.75 \%)$ \\
CS $(10 \mu \mathrm{g})$ & $12(14.63 \%)$ & 0 & $68(85 \%)$ \\
\hline
\end{tabular}

Gentamicin: GEN, Streptomycin: STR, Aztreonam: AZT, Ticarcillin: TC, Imipenem: IPM, Amoxicillin-clavulanic-acid: AMC, Cephalexin: CL, Sulfamethoxazole-trimethoprim: SXT, Colistin Sulfat: Cs, Chloramphenicol: C, Cefotaxim: CTX, Ceftriaxon: CTR, Ciprofloxacin: CIP, Nalidixic acid: NA, Tetracycline: TE 
Table 5. Multiple antimicrobial resistance patterns of Salmonella serovars.

\begin{tabular}{|c|c|c|c|c|c|c|c|c|c|c|c|}
\hline \multirow{2}{*}{$\begin{array}{l}\text { Antimicrobial } \\
\text { resistance } \\
\text { pattern* }\end{array}$} & \multicolumn{11}{|c|}{ Number of resistant Salmonella serovars } \\
\hline & $\begin{array}{l}\text { Brancaster } \\
\text { (1) }\end{array}$ & $\begin{array}{l}\text { Chester } \\
\text { (10) }\end{array}$ & $\begin{array}{l}\text { Derby } \\
(18)\end{array}$ & $\begin{array}{l}\text { Essen } \\
\text { (1) }\end{array}$ & $\begin{array}{l}\text { Hato } \\
\text { (5) }\end{array}$ & $\begin{array}{l}\text { Kentucky } \\
\text { (1) }\end{array}$ & $\begin{array}{l}\text { Ouakam } \\
\text { (1) }\end{array}$ & $\begin{array}{l}\text { Group Z } \\
\text { (3) }\end{array}$ & $\begin{array}{l}\text { Group B } \\
\text { (1) }\end{array}$ & $\begin{array}{l}\text { untypable } \\
\text { (9) }\end{array}$ & $\begin{array}{l}\text { Total } \\
(\mathbf{5 0})\end{array}$ \\
\hline E- AUG & & & 3 & & & & & & & 1 & 4 \\
\hline E- TC & & 2 & & 1 & 1 & & & & & & 4 \\
\hline E- TE & & & 2 & & & & & & & & 2 \\
\hline E- AUG- TC & & 1 & & & 1 & & 1 & 1 & & 1 & 5 \\
\hline E- AUG- TE & & & 4 & & & & & & & & 4 \\
\hline E- TC- CL & & 1 & & & & & & & & & 1 \\
\hline E- TC- CS & & & & & & & & & & 1 & 1 \\
\hline E- AUG- TC- CTX & & & 1 & & & & & 1 & & 1 & 3 \\
\hline E- AUG- TC- TE & & & 3 & & & & & & & & 3 \\
\hline E- AUG- AZT- TE & & & 1 & & & & & & & & 1 \\
\hline $\begin{array}{l}\text { E- AUG- CTR- } \\
\text { CTX }\end{array}$ & & & & & & & & & & 1 & 1 \\
\hline E- AUG- CTX- CS & & & & & & & & & & 1 & 1 \\
\hline E- TC- CTX- CS & & & & & & & & & & 1 & 1 \\
\hline E- S- TE- SXT & 1 & & & & & & & & & & 1 \\
\hline $\begin{array}{l}\text { E- AUG- AZT- } \\
\text { TC- CRO }\end{array}$ & & & & & & & & & 1 & & 1 \\
\hline $\begin{array}{l}\text { E- AUG- TC- } \\
\text { CTX- CS }\end{array}$ & & & 1 & & & & & & & & 1 \\
\hline $\begin{array}{l}\text { E- AUG- TC- } \\
\text { SXT- CS }\end{array}$ & & 1 & & & & & & & & & 1 \\
\hline $\begin{array}{l}\text { E- AUG- TC- S- } \\
\text { TE }\end{array}$ & & & & & 1 & & & & & & 1 \\
\hline $\begin{array}{l}\text { E- AUG- TC- } \\
\text { GEN- CS }\end{array}$ & & 1 & & & & & & & & & 1 \\
\hline $\begin{array}{l}\text { E- AUG- S- TE- } \\
\text { SXT }\end{array}$ & & & & & & & & 1 & & & 1 \\
\hline $\begin{array}{l}\text { E- TC- CL- TE- } \\
\text { CS }\end{array}$ & & & 1 & & & & & & & & 1 \\
\hline $\begin{array}{l}\text { E- TC- CTX- } \\
\text { GEN- CS }\end{array}$ & & & 1 & & & & & & & & 1 \\
\hline $\begin{array}{l}\text { E- AUG- TC- } \\
\text { CRO- GEN- CS }\end{array}$ & & 1 & & & & & & & & & 1 \\
\hline $\begin{array}{l}\text { E- AUG- AZT- } \\
\text { TC- CTX- C }\end{array}$ & & & & & & & & & & 1 & 1 \\
\hline $\begin{array}{l}\text { E- AUG- TC- S- } \\
\text { TE- SXT }\end{array}$ & & & & & 1 & & & & & & 1 \\
\hline $\begin{array}{l}\text { E- TC- S- GEN- } \\
\text { TE- SXT }\end{array}$ & & & & & & 1 & & & & & 1 \\
\hline $\begin{array}{l}\text { E- AUG- AZT- } \\
\text { TC- CTX- CIP- CS } \\
\text { E- AUG- AZT- }\end{array}$ & & & & & 1 & & & & & & 1 \\
\hline $\begin{array}{l}\text { TC- CTX- GEN- } \\
\text { CS } \\
\text { E- AUG- TC- }\end{array}$ & & 2 & & & & & & & & & 2 \\
\hline $\begin{array}{l}\text { CTR- GEN- TE- } \\
\text { CIP }\end{array}$ & & 1 & & & & & & & & & 1 \\
\hline $\begin{array}{l}\text { E- AUG- AZT-TC- } \\
\text { CTX- TE- SXT- }\end{array}$ & & & & & & & & & & 1 & 1 \\
\hline $\begin{array}{l}\text { CS } \\
\text { E- AUG- AZT- }\end{array}$ & & & & & & & & & & & \\
\hline $\begin{array}{l}\text { TC- CTX- S- TE- } \\
\text { CS }\end{array}$ & & & 1 & & & & & & & & 1 \\
\hline $\begin{array}{l}\text { Resistance to } 3 \text { - } 4 \\
\text { antibiotics }\end{array}$ & 1 & 2 & 9 & 0 & 1 & 0 & 1 & 2 & 0 & 6 & 22 \\
\hline $\begin{array}{l}\text { Resistance to } 5 \text { or } \\
\text { more antibiotics }\end{array}$ & 0 & 6 & 3 & 0 & 3 & 1 & 0 & 1 & 1 & 2 & 17 \\
\hline
\end{tabular}

Gentamicin: GEN, Streptomycin: STR, Aztreonam: AZT, Ticarcillin: TC, Imipenem: IPM, Amoxicillin-clavulanic-acid: AMC, Cephalexin: CL, Sulfamethoxazole-trimethoprim: SXT, Colistin Sulfat: Cs, Chloramphenicol: C, Cefotaxim: CTX, Ceftriaxon: CTR, Ciprofloxacin: CIP, Nalidixic acid: NA, Tetracycline: TE 


\section{Discussion}

Salmonella infections constitute a public health problem in low-income countries because of the weakness of control measures and not following good food safety practices.

In the present study, Salmonella was detected in $24.69 \%$ of all the poultry intestines samples analyzed with $20.45 \%$ in slaughtered chicken intestines and $22.26 \%$ in slaughtered guinea fowl intestines. In contrast, a high prevalence of Salmonella in slaughtered poultry intestines were detected in the studies conducted by Kagambega et al. (2013) (55\%) [18] and 2018 (52.42\%) [9] in Burkina Faso; Andoh et al. (2016) in Ghana (47\%) [19] and Bai et al. (2015) in China $(45.2 \%)$ [20]. This difference could be explained by sampling conditions, isolation method and period of sampling. However, the lowest prevalence of Salmonella in poultry was found in Egypt (17\%) by Ammar et al., 2016 [21] and in India (6.31\%) by Mir et al. (2015) [22].

The present study shows a different prevalence of salmonella in chicken (20.45\%) and guinea fowl (22.26\%). The rate of Salmonella contamination in chicken found in our study is high compared to the result found by Parvej et al., 2016 in chicken (7.33\%) from Bangladesh [23]. However, a high prevalence (61.1\%) of Salmonella in chicken was found in Vietnam by Tu et al., 2014 [24]. By contrast, a very low prevalence of Salmonella was found in Benin from guinea fowl intestines $(6.4 \%)$ by Boko et al., 2013 [25]. These differences could be explained by the difference in types of poultry species and farming conditions.

The prevalence of Salmonella in slaughtered poultry including chicken and guinea fowl intestines in this study is worrying because these Salmonella strains can contaminate poultry carcasses if the hygienic practices failed during evisceration. Moreover, most of the poultry carcasses sellers are doing the entire steps of poultry processing in the same place (slaughtering, scalding, plucking, evisceration) and carcasses are stored at ambient temperature for selling without any cooling system, which conditions will increase surely the multiplication of the pathogen in contaminated carcasses [6]. The finding in this study shows a high risk for consumer health if some crosscontamination occurred during carcasses preparation. It is well documented that Salmonella infections in humans have been associated with raw chicken [26, 27].

Salmonella serotypes Brancaster, Chester, Derby, Essen, Hato, Kaapstad, Kentucky, Ouakam and Typhimurium were identified in the present study, with Derby being the most prevalent serotype in chicken and Guinea fowl. Similar results were found by Kagambèga et al. (2013) [18] in poultry intestines, where Salmonella Derby was the most prevalent serotype found in poultry. In contrast, LópezMartín et al. (2016) [28] reported Salmonella Enteritidis as a predominant serotype in chicken and Salmonella Typhimurium plus Salmonella Derby and Salmonella Enteritidis as predominant serotypes in pigs. Salmonella Typhimurium was most prevalent in guinea fowl compare to chicken intestines. This finding shows that guinea fowl could be a principal reservoir for Salmonella Typhimurium. The nine Salmonella serotypes identified in this study have been isolated in patients with diarrhea in Burkina Faso [29, 30]. These findings show that chicken and/or guinea fowl can be considered as the main reservoirs for Salmonella and constitutes a potential source for human salmonellosis in Burkina Faso. This hypothesis is true since, there is a lack of a good sanitation and water quality management system in the country, particularly in rural areas, where many people living with poultry running freely in the household. Moreover, there is no abattoir for poultry in Burkina Faso, and poultry meat sellers are slaughtering in open market places without any veterinary control. Therefore, this study shows a serious need for quality checks and surveillance programs in order to reduce the risk of salmonellosis.

The antibiotics susceptibility results in this study highlighted the higher resistance of the isolates to Erythromycin (100\% of chicken and guinea fowl isolates) followed by Amoxicillin-clavulanic acid (63.33\% of chicken isolates and $60.97 \%$ of guinea fowl isolates), Ticarcillin (60\% of chicken isolates and $51.26 \%$ of guinea fowl isolates) and Tetracycline $(31.66 \%$ of chicken isolates and $35.36 \%$ of guinea fowl isolates). These results are similar to those of other studies $[31,32]$. This finding confirmed that in poultry, these drugs are used either for disease treatment or as growth promoters without prescription because they are cheap and easily affordable. In addition, the feed is leading to the development of resistance in the enteric bacterial flora of poultry antibiotic Salmonella However, lower resistance rates to Chloramphenicol $(2.43 \%$ for chicken isolates; $1.66 \%$ for guinea fowl isolates); Ciprofloxacin (9.75\% for chicken isolates, $3.33 \%$ for guinea fowl isolates), Imipenem ( $0 \%$ for chicken isolates; $1.21 \%$ for guinea fowl isolates); Sulfamethoxazole-trimethoprim (8.33\% for chicken isolates; $1.21 \%$ for guinea fowl isolates) and nalidixic acid ( $0 \%$ for chicken isolates; $1.21 \%$ for guinea fowl isolates) were observed. In contrast, high resistance rates to Chloramphenicol (27.2\%), Nalidixic acid (28.8\%) was reported from poultry isolates by Tu et al., 2014 in Vietnam [24]; Gharieb et al., 2015 also reported higher resistance rates to chloramphenicol (50\%) and ciprofloxacin (30\%) from poultry Salmonella in Egypt [31]. This finding is worrying because resistance to the third generation antibiotics in a strain isolated in poultry means that these drugs are also used by veterinarians and their effectiveness will decrease in the treatment of human salmonellosis.

In the present study, $35.97 \%$ of the Salmonella isolates show multiple resistance to the tested antibiotics with 31 different resistances patterns lowest prevalence of MDR Salmonella (30.1\%) has been reported by $\mathrm{Tu}$ et al., 2014 [24]. Many serotypes were resistant to 4 or 8 antibiotics in this study, one Kentucky were resistant to six antibiotics (E- TC- S- GEN- TESXT), three Chester resistant to seven antibiotics (E- AUG- TCCTR- GEN- TE- CIP) one Derby and one Salmonella spp were found to be resistant to eight antibiotics ( E- AUG- AZT- TCCTX- S- TE- CS). These results are nearly similar to those of 
other studies [33, 34], reflecting the use of antibiotics in animal husbandry. Several studies demonstrated that the increase of antimicrobial resistance among Salmonella strains in recent years can be attributed to the selection pressure created by the inappropriate application of antibiotics in veterinary and human medicine [18, 22]. MDR Salmonella Kentucky was isolated from chicken in the present study. This finding corroborates with the report of USDA and FDA where Salmonella Kentucky has been the most common serotype isolated from chickens and Chicken meat $[35,36]$. A highly resistant clone of Salmonella Kentucky (MLST type ST198), has been reported to be isolated in Canada and in Europe in travelers returning from Asia and Africa [37]. MDR Salmonella has been identified as an emerging pathogen causing invasive bloodstream infections, especially in sub-Saharan Africa [38]. The emergence of multidrug-resistant (MDR) Salmonella strains constitutes a public health risk and potentially affects the efficacy of drug treatment in humans. The present study shows the urgent need to control the use of antibiotics in veterinary and human medicine to limit the spreading of MDR Salmonella strains. The Salmonella Typhimurium isolated in this study was resistant to one antibiotic (erythromycin). This is in contrast to the result found by Kagambega et al., 2013 [18] who found that all Salmonella Typhimurium isolated from slaughtered poultry were Penta-resistant with the same sequence type ST313. Highly multidrug-resistant Salmonella Typhimurium was also reported in chicken by many authors [39, 33]. The finding in this study could be explained by the fact that there is an emergence of a new Salmonella Typhimurium clone among poultry species.

\section{Conclusion}

In conclusion, the data presented here indicate that chicken and guinea fowl are reservoirs of antibiotic-resistant Salmonella. There is potential for these antibiotic-resistant bacteria to be transferred to humans through contaminated poultry and poultry products Salmonella not only poses a serious threat to public health but also causes huge economic losses by generating mortality and morbidity to the poultry industry. Multidrug resistance of Salmonella is a public health problem and there is an urgent need to reinforce the surveillance of the use of antibiotics by farmers, veterinarians, and physicians. Therefore, the continued development of methods to reduce the risk of foodborne pathogens in poultry is critical.

\section{Ethical Considerations}

Permission to conduct this study was obtained from the poultry carcasses sellers and the study protocol was approved by the Ethical Committee of Burkina Faso.

\section{Competing Interests}

The authors declare that they have no competing interests.

\section{Authors' Contributions}

$\mathrm{CB}$ carried out strain isolation and characterization, $\mathrm{AK}$ and $\mathrm{CB}$ drafted the manuscript, NB and MC supervised and participated in writing the manuscript. All authors read, commented on and approved of the final manuscript.

\section{Acknowledgements}

This study was funded by the International Foundation for Science (IFS) grant E/5668-1 to Soutongnooma Caroline BOUDA and SCAC- Embassy of France. We thank the technicians of Anses, Hygiene, and Quality of Poultry and Pig Products Unit, Site des Croix, Ploufragan, France for the technical support during Salmonella serotyping.

\section{References}

[1] Padungtod, P., and J. B. Kaneene. 2006. Salmonella in food animals and humans in northern Thailand. Inernational Journal Food Microbiology, 108: 346-354.

[2] Guibourdenche, M., P. Roggentin, M. Mikoleit, P. I. Fields, J. Bockemühl, P. A. Grimont, and F. X. Weill. 2010. Supplement 2003-2007 (No. 47) to the White-Kauffmann-Le Minor scheme. Research in Microbiology 161: 26-29.

[3] Scallan, E., P. M. Griffin, F. J. Angulo, R. V. Tauxe, and R. M. Hoekstra. 2011. Foodborne illness acquired in the United States--unspecified agent Salmonella Emerging Infectious Diseases 17: 16-22.

[4] Duc VM, Nakamoto Y, Fujiwara A, Toyofuku H, Obi T, Chuma T. 2019. Prevalence of Salmonella in broiler chickens in Kagoshima, Japan in 2009 to 2012 and the relationship between serovars changing and antimicrobial resistance. BMC Vet Res. 15:108. doi: 10.1186/s12917019-1836-6.

[5] World Health Organization. 2015. WHO estimates of the global burden of foodborne diseases: foodborne disease burden epidemiology reference group 2007-2015. 255p. http://apps.who.int/iris/bitstream/10665/199350/1/978924156 5165 eng.pdf?ua $=1$

[6] Kagambèga, A., K. Haukka, A. Siitonen, A. S. Traoré, and N. Barro. 2011. Prevalence of Salmonella enterica and the hygienic indicator Escherichia coli in raw meat at markets in Ouagadougou, Burkina Faso. Journal Food Protection 74: $1547-1551$

[7] Simporé, J., D. Ouermi, D. Ilboudo, A. Kabre, B. Zeba, V Pietra, S. Pignatelli, J. B. Nikiema, G. B. Kabre, S. Caligaris, F. Schumacher, and Castelli F. 2009. Aetiology of acute gastro-enteritis in children at Saint Camille Medical Centre, Ouagadougou, Burkina Faso. Pakistan Journal Biology Science; 12: 258-263.

[8] EFSA and ECDC (European Food Safety Authority and European Centre for Disease Prevention and Control), 2017. The European Union summary report on trends and sources of zoonoses, zoonotic agents and food-borne outbreaks in 2016. https://doi.org/10.2903/j.efsa.2017.5077. https://efsa.onlinelibrary.wiley.com/doi/abs/10.2903/j.efsa.201 7.5077 
[9] Kagambèga A, Thibodeau A, Trinetta V., Soro K. D.,. Sama F. N., Bako E,. Bouda S. C, Wereme A, Fravalo P., Barro N. 2018. Salmonella spp. and Campylobacter spp. in poultry feces and carcasses in Ouagadougou, Burkina Faso. Food science and nutrition, DOI: 10.1002/fsn3.725.

[10] Rouger A, Tresse O, Zagorec M. 2017. Bacterial contaminants of poultry meat: sources, species, and dynamics. Microorganisms, 5: E50.

[11] Alders, R. 2005. L'aviculture: source de profit et de plaisir. Organisation des Nations Unies pour l'alimentation et l'agriculture: Rome, $21 \mathrm{p}$.

[12] Berrang, M. E., J. S. Bailey, S. F. Altekruse, W. K. Jr. Shaw, B. L. Patel, R. J. Meinersmann, and P. J. FedorkaCray. 2009. Prevalence, serotype, and antimicrobial resistance of Salmonella on broiler carcasses postpick and postchill in 20 U.S. processing plants. J Food Prot. Aug; 72(8): 1610-5.

[13] International Organization for Standardization (ISO) 65791:2017. Microbiology of the food chain - Horizontal method for the detection, enumeration and serotyping of Salmonella - Part 1: Detection of Salmonella spp.

[14] Quinn, P. J., B. K. Markey, F. C. Leonard, E. S. FitzPatrick, S. Fanning, and P. J. Hartigan. 2011. Enterobacteriaceae. In Veterinary Microbiology and Microbial Disease 2nd edn (pp. 263_286).

[15] Popoff, M. Y., J. Bockemuhl, and L. L. Gheesling. 2004. Supplement 2002 (no. 46) to the Kauffmann-White scheme. Research Microbiology. 155: 568-570.

[16] Bauer, A. W., W. M. M. Kirby, J. C. Sherries, and M. Turck. 1966. Antibiotic susceptibility testing. Am. J. Pathol. 45: 493496.

[17] EUCAST. European Committee on Antimicrobial Susceptibility Testing breakpoint table for interpretation of MICs and zone diameters 2017. http://www.sfm microbiologie.

org/UserFiles/files/casfm/CASFMV1_0_MARS_2017.pdf

[18] Kagambèga, A, T. Lienemann, L. Aulu, A. S. Traoré, N. Barro, A. Siitonen, and K Haukka. 2013. Prevalence and characterization of Salmonella enterica from the intestines of cattle, poultry, swine and hedgehogs in Burkina Faso and their comparison to human Salmonella isolate. Salmonella. BMC Microbiology 13: 253.

[19] Andoh LA, Dalsgaard A, Obiri-Danso K, Newman MJ, Barco L, Olsen JE. 2016. Prevalence and antimicrobial resistance of Salmonella serovars isolated from poultry in Ghana Epidemiol Infect. 144: 3288-3299.

[20] Bai, L., R. Lan, X. Zhang, S. Cui, J. Xu, Y. Guo, F. Li, and D. Zhang. 2015. Prevalence of Salmonella isolates from chicken and pig slaughterhouses and emergence of ciprofloxacin and cefotaxime co-resistant Salmonella enterica serovar Indiana in Henan, China. PLoS One 10: e0144532

[21] Ammar, A. M, A. A. Mohamed, M. I. A. El-Hamid, and M. M. El-Azzouny. 2016. Virulence genotypes of clinical Salmonella Serovars from broilers in Egypt. J Infect Dev Ctries. 10(4):337-346. doi:10.3855/jidc.7437

[22] Mir, I. A., S. K. Kashyap, and S. Maherchandani. 2015. Isolation, serotype diversity and antibiogram of Salmonella enterica isolated from different species of poultry in India.
Asian Pac J Trop Biomed; 5: 561-567.

[23] Parvej, M. S., K. H. M. Nazmul Hussain Nazir, M. B. Rahman, M. Jahan, M. F. R. Khan, and M. Rahman. 2016. Prevalence and characterization of multi-drug resistant Salmonella Enterica serovar Gallinarum biovar Pullorum and Gallinarum from chicken, Veterinary World 9(1): 6570 .

[24] Tu, L. T., N. V. Hoang, N. V. Cuong, J. Campbell, J. E. Bryant, N. T. Hoa, B. T. Kiet, C. Thompson, D. T. Duy, V. V. Phat, V. B. Hien, G. Thwaites, S. Baker, and J. J. CarriqueMas. 2015. High levels of contamination and antimicrobialresistant non-typhoidal Salmonella serovars on pig and poultry farms in the Mekong Delta of Vietnam. Epidemiol. Infect. 413, 1-13.

[25] Boko, C. K., T. M. Kpodekon, J. N. Duprez, H. Imberechts, B. Taminiau, S. Bertrand, and J. G. Mainil. 2013. Identification and typing of Salmonella enterica serotypes isolated from guinea fowl (Numida meleagris) farms in Benin during four laying seasons (2007 to 2010), Avian Pathology, 42:1, 1-8, DOI: $10.1080 / 03079457.2012 .751484$

[26] Harrison, W. A., C. J. Grifftih, D. Tennant, and A. C. Peters. 2001. Incidence of Campylobacter and Salmonella isolated from retail chicken and associated packaging in South Wale Salmonella. Letters in Applied Microbiology, 33, 450-454.

[27] Hernandez, T., A. Sierra, C. Rodriguez-Alvarez, A. Torres, M. P. Arevalo, M. Calvo, and A. Arias. 2005. Salmonella enterica Serotypes Isolated from Imported Frozen Chicken Meat in the Canary Island Salmonella. Journal of Food Protection, Vol. 68, No. 12, 2005, Pages 2702-2706.

[28] López-Martín, J. I, D. González-Acuña, C. A. García, and L. O. Carrasco. 2016. Isolation and Antimicrobial Susceptibility of Salmonella Typhimurium and Salmonella Enteritidis in fecal samples from Animal Salmonella. Journal of Antimicrobial agents. 2: 109. doi: 10.4172/antimicro.1000109

[29] Bonkoungou, I. J. O., K. Haukka, M. Österblad, A. J. Hakanen, A. S. Traoré, N. Barro, and A. Siitonen. 2013. Bacterial and viral aetiology of childhood diarrhea in Ouagadougou, Burkina Faso. BMC Pediatrics.; 13: 1-6.

[30] Dembélé, R., A. Konaté, I. J. O. Bonkoungou, A. Kagambèga, K. Konaté, T. S. Bagré, A. S. Traoré, and N. Barro. 2014. Serotyping and antimicrobial susceptibility of Salmonella isolated from children under five years of age with diarrhea in rural Burkina Faso. African Journal of Microbiology Research $8,3157-3163$.

[31] Gharieb Rasha. M., H. Tartor Yasmine, and H. E. Khedr Mariam. 2015. Non-Typhoidal Salmonella in poultry meat and diarrheic patients: prevalence, antibiogram, virulotyping, molecular detection and sequencing of class I integrons in multidrug resistant strain Salmonella. Gut pathogens. 7:34 DOI 10.1186/s13099-015-0081-1.

[32] Soomro, A. H., M. Khaskheli, M. B. Bhutto, G. Shah, A. Memon, and P. Dewani. 2010. Prevalence and antimicrobial resistance of Salmonella serovars isolated from poultry meat in Hyderabad, Pakistan. Turkish journal of veterinary and animal sciences; 34(5): 455-60.

[33] Van, H. T. T., G. Moutafis, T. Istivan, L. T. Tran, and P. J. Coloe. 2007. Detection of Salmonella spp. in raw food samples from Vietnam and characterization of their antibiotic resistance. Appl. Environ. Microbiol., 73, 6885-6890. 
[34] Wilson, I. G. 2004. Antimicrobial resistance of Salmonella in retail chickens imported chicken portions, and human clinical specimens. J. Food Prot., 67, 1220-1225.

[35] USDA. (2008). National Antimicrobial Resistance Monitoring System for Enteric Bacteria (NARMS). Veterinary isolates final report, slaughter isolates, 2006. USDA, Washington, DC. http://www.arSalmonellausda.gov/sp2UserFiles/Place/661205 08/NARMS/narms_2006/NARMS2006.pdf.

[36] FDA. 2008. National Antimicrobial Resistance Monitoring System for Enteric Bacteria (NARMS). Retail meat annual report, 2006. FDA, Bethesda MD. http://www.fda.gov/downloads/AnimalVeterinary/SafetyHealt $\mathrm{h} /$ AntimicrobialResistance/NationalAntimicrobial Resistance Monitoring System/UCM073302.pdf.
[37] Mulvey, M. R., Boyd, D. A., Finley, R., Fakharuddin, K., Langner, S., Allen, V....Wylie, J. 2013. CiprofloxacinResistant Salmonella enterica Serovar Kentucky in Canada. Emerging Infectious Diseases, 19(6), 999-1001. https://dx.doi.org/10.3201/eid1906.121351.

[38] Feasey, N. A., G. Dougan, R. A. Kingsley, R. S. Heyderman, and M. A. Gordon. 2012. Invasive non-typhoidal Salmonella disease: an emerging and neglected tropical disease in Africa. Lancet. 379: 2489-99.

[39] Turki, Y., I. Mehr, H. Ouzari, A. Khessairi, and A. Hassen. 2014. Molecular typing, antibiotic resistance, virulence gene and biofilm formation of different Salmonella enterica serotypes. J Gen Appl Microbiol. 60(4): 123-30. 